\title{
Troponin T and Quantitative ST-Segment Depression Offer Complementary Prognostic Information in the Risk Stratification of Acute Coronary Syndrome Patients
}

Padma Kaul, PHD,* L. Kristin Newby, MD,* Yuling Fu, MD, $†$ Vic Hasselblad, PHD,* Kenneth W. Mahaffey, MD,* Robert H. Christenson, PHD, $\ddagger$ Robert A. Harrington, MD,*

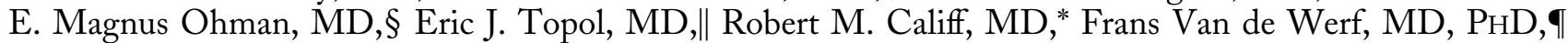
Paul W. Armstrong, MD, $\S$ for the PARAGON-B Investigators

Durham and Chapel Hill, North Carolina; Edmonton, Alberta, Canada; Baltimore, Maryland; Cleveland, Obio; and Leuven, Belgium

OBJECTIVES Our primary objective was to examine the prognostic relationship between baseline quantitative ST-segment depression (ST $\downarrow$ ) and cardiac troponin $\mathrm{T}$ (cTnT) elevation. The secondary objectives were to: 1 ) examine whether ST $\downarrow$ provided additional insight into therapeutic efficacy of glycoprotein IIb/IIIa therapy similar to that demonstrated by cTnT; and 2) explore whether the time to evaluation impacted on each marker's relative prognostic utility.

BACKGROUND The relationship between the baseline electrocardiogram (ECG) and cTnT measurements in risk-stratifying patients presenting with acute coronary syndromes (ACS) has not been evaluated comprehensively.

METHODS The study population consisted of 959 patients enrolled in the cTnT substudy of the Platelet IIb/IIIa Antagonism for the Reduction of Acute coronary syndrome events in a Global Organization Network (PARAGON)-B trial. Patients were classified as having no ST $\downarrow$ (n $=387), 1 \mathrm{~mm} \mathrm{ST} \downarrow(\mathrm{n}=433)$, and ST $\downarrow \geq 2 \mathrm{~mm}(\mathrm{n}=139)$. Forty-percent $(\mathrm{n}=381)$ were classified as cTnT-positive based on a definition of $\geq 0.1 \mathrm{ng} / \mathrm{ml}$.

RESULTS Six-month death/(re)myocardial infarction rates were $8.4 \%$ among cTnT-negative patients with no ST $\downarrow$ and $26.8 \%$ among cTnT-positive patients with ST $\downarrow \geq 2 \mathrm{~mm}$. On ECGs done after $6 \mathrm{~h}$ of symptom onset, ST $\downarrow \geq 2 \mathrm{~mm}$ was associated with higher risk compared to its presence on ECGs done earlier (odds ratio [OR] 7.3 vs. 2.1). In contrast, the presence of elevated cTnT within $6 \mathrm{~h}$ of symptom was associated with a higher risk of adverse events compared with elevations after 6 h (OR 2.4 vs. 1.5).

CONCLUSIONS Quantitative ST $\downarrow$ and cTnT status are complementary in assessing risk among ACS patients and both should be employed to determine prognosis and assist in medical decision making. (J Am Coll Cardiol 2003;41:371-80) (C) 2003 by the American College of Cardiology Foundation

The introduction of cardiac troponin measurements into routine clinical practice has been an important milestone in the continuing quest for more effective early risk stratification of patients presenting with acute coronary syndromes (ACS). Higher cardiac troponin levels are associated with worse outcomes in both ST-segment elevation myocardial infarction (MI) (1) and non-ST-segment elevation ACS patients $(2,3)$. In addition to a prognostic role, elevated levels of this biomarker appear to effectively identify patients with an increased likelihood of intracoronary thrombi and complex coronary lesions (4-6) which are most likely to

From the *Duke Clinical Research Institute, Durham, North Carolina; †University of Alberta, Edmonton, Alberta, Canada; $\ddagger$ University of Maryland Medical System, Baltimore, Maryland; §University of North Carolina Medical Center, Chapel Hill, North Carolina; \# Cleveland Clinic Foundation, Cleveland, Ohio; and the Catholic University Hospital, Leuven, Belgium. This study was supported by F. Hoffmann-La Roche Ltd., Basel, Switzerland; Roche Diagnostics Corporation, Indianapolis, Indiana; and Roche Diagnostics $\mathrm{GmbH}$, Mannheim, Germany. Dr. Kaul was supported by a fellowship award from the Canadian Institute of Health Research, Heart and Stroke Foundation of Canada, and the Alberta Heritage Foundation for Medical Research.

Manuscript received February 19, 2002; revised manuscript received September 16, 2002, accepted October 31, 2002. benefit from either antithrombin or intravenous glycoprotein (GP) IIb/IIIa inhibitor therapy (7-13).

Another diagnostic tool, the presenting 12-lead electrocardiogram (ECG), provides the earliest available objective information for risk stratification of most ACS patients (14-17). Whereas the qualitative importance of STsegment depression (ST $\downarrow$ ) on the baseline ECG of ACS patients is recognized clinically, quantification of this phenomenon is rarely used in clinical practice. In a recent evaluation of patients from the Platelet IIb/IIIa Antagonism for the Reduction of Acute coronary syndrome events in a Global Organization Network (PARAGON)-A study, we documented the prognostic importance of quantitative $\mathrm{ST} \downarrow$ for one-year mortality among non-ST-segment elevation ACS patients (18). Patients with ST $\downarrow$ of $\geq 2 \mathrm{~mm}$ in two contiguous leads were approximately six times (odds ratio $[\mathrm{OR}] 5.73$; 95\% confidence interval $[\mathrm{CI}]: 2.8,11.6$ ) more likely to die within one year than patients with no with ST $\downarrow$.

Because cardiac troponin $\mathrm{T}(\mathrm{c} T \mathrm{n} \mathrm{T})$ takes a finite time to appear whereas the ECG is more immediately responsive to an acute ischemic event, their potential complementary role 


$$
\begin{aligned}
& \text { Abbreviations and Acronyms } \\
& \text { ACS = acute coronary syndromes } \\
& \text { CI }=\text { confidence interval } \\
& \mathrm{CV}=\text { coefficient of variation } \\
& \mathrm{cTnT}=\text { cardiac troponin } \mathrm{T} \\
& \mathrm{ECG}=\text { electrocardiogram } \\
& \mathrm{GP}=\text { glycoprotein } \\
& \mathrm{IQR}=\text { interquartile range } \\
& \mathrm{MI}=\text { myocardial infarction } \\
& \text { OR = odds ratio } \\
& \text { PARAGON = Platelet IIb/IIIa Antagonism for the }
\end{aligned}
$$

in risk-stratifying patients presenting with ACS is of interest. The relationship between these two fundamental diagnostic tests assessed quantitatively in a core laboratory has not been evaluated comprehensively and is the primary objective of the current study. The secondary objectives of the study were to: 1) examine whether quantitative $\mathrm{ST} \downarrow$ provided additional insight into therapeutic efficacy of GP IIb/IIIa therapy similar to that demonstrated by cTnT; and 2) explore whether the time to evaluation (i.e., time between symptom onset and ECG or to when cTnT was drawn) had an impact on each marker's relative prognostic utility.

\section{METHODS}

Patient population. The study population consisted of patients enrolled in the troponin $\mathrm{T}$ substudy of the PARAGON-B trial. Both the overall PARAGON-B study and the troponin substudy have been described earlier $(7,19)$. Briefly, the PARAGON-B study enrolled 5,225 patients $\geq 21$ years of age with non-ST-segment elevation ACS who presented within $12 \mathrm{~h}$ of symptom onset and who had symptoms lasting $\geq 10 \mathrm{~min}$. All patients had evidence of cardiac ischemia, based on either ECG changes or elevated creatine kinase-MB or troponin $\mathrm{T}$ or I by local laboratory standards. Patients were randomized in a blinded fashion to either lamifiban or placebo therapy. The primary end point was the composite of death, MI, or severe, recurrent ischemia at 30 days. Six-month death and (re)MI were assessed as secondary end points. The institutional review board approved the substudy protocol at each site.

Cardiac troponin measurement. Of the 5,225 PARAGON$\mathrm{B}$ patients, 1,160 patients were prospectively enrolled in the troponin $\mathrm{T}$ substudy. All cTnT measurements were performed with the third-generation troponin T STAT electrochemiluminescent immunoassay on the Elecsys 2010 system (Roche Diagnostics Corporation, Indianapolis, Indiana) at a Clinical Laboratory Improvement Act-accredited core lab at the Department of Pathology, University of Maryland School of Medicine. The minimum detectable concentration was $0.01 \mathrm{ng} / \mathrm{ml}$, and the imprecision (coefficient of variation $[\mathrm{CV}]$ ) observed at the core lab was $6.2 \%$ at both 0.15 and $6.0 \mathrm{ng} / \mathrm{ml}$ concentrations, consistent with the specifications of the manufacturer of a $6.0 \% \mathrm{CV}$ at $5.07 \mathrm{ng} / \mathrm{ml}$ and 9.3\% CV at $0.10 \mathrm{ng} / \mathrm{ml}$ for this U.S. Food and Drug Administration cleared assay. Imprecision $(\mathrm{CV})$ at low troponin $\mathrm{T}$ concentrations was validated as $10 \%$ at a concentration of $0.03 \mathrm{ng} / \mathrm{ml}$ by the core lab. These data are consistent with the imprecision specified in the manufacturer's insert of $6 \%$ at $0.09 \mathrm{ng} / \mathrm{ml}, 7 \%$ at $0.06 \mathrm{ng} / \mathrm{ml}, 10 \%$ at $0.03 \mathrm{ng} / \mathrm{ml}$, and $30 \%$ at $0.01 \mathrm{ng} / \mathrm{ml}$. Patients with cTnT levels $>0.1 \mathrm{ng} / \mathrm{ml}$ were categorized as cTnT-positive. Thirty-day and six-month end points were used as determined for the main PARAGON-B study (7). Baseline ECG data were available for 1,112 (96\%) cTnT substudy patients.

ECG parameters. All ECG data were evaluated centrally at the ECG core laboratory at the University of Alberta. The ECGs were recorded in 12-lead format at a paper speed of $25 \mathrm{~mm} / \mathrm{s}$. The ST $\downarrow$ was judged to be present if the J point was depressed by $1 \mathrm{~mm}$ or more and was followed by a horizontal or downward sloping ST-segment for at least $0.08 \mathrm{~s}$ in one or more of the 12 leads except aVR.

For purposes of our analysis, ST $\downarrow$ was categorized into three mutually exclusive groups: no ST $\downarrow, 1 \mathrm{~mm} \mathrm{ST} \downarrow$ in two contiguous leads, and ST $\downarrow \geq 2 \mathrm{~mm}$ in two contiguous leads. Patients with potentially confounding factors affecting ECG interpretation, including left bundle branch block, right bundle branch block, left ventricular hypertrophy, ventricular pacemakers, or with incomplete ECG were excluded from the analysis.

Outcomes. The relationships between baseline STsegment status and cTnT positivity and both short- and long-term outcomes, namely 30-day and 6-month (re)MI after admission and/or death, were examined. Six-month follow-up status was available for $97 \%$ of the patients enrolled in the PARAGON-B troponin T substudy.

Treatment effect. In the troponin $T$ substudy, lamifiban was associated with a significant reduction in the 30-day primary end point among cTnT-positive patients (from $19.4 \%$ to $11.0 \% ; \mathrm{p}=0.01)$ resulting in rates that were comparable to those among cTnT-negative patients $(11.2 \%$ for placebo vs. $10.8 \%$ for lamifiban) (7). We examined whether the therapeutic response to treatment among patients with positive troponin persisted at six months. The relationship between the extent of ST $\downarrow$ and six-month death/(re)MI by treatment assignment was also examined to determine whether the marker provided additional insights into the therapeutic efficacy of GP IIb/IIIa therapy.

Time effect. We conducted exploratory analyses to determine whether the time from symptom onset to ECG and to when cTnT samples were drawn had an impact on the prognostic significance of the markers. Patients were classified according to whether the ECG and $\mathrm{cTnT}$ were done within $6 \mathrm{~h}$ of symptom onset or later. The relationship of ST $\downarrow$ and troponin positivity to six-month death/(re)MI outcomes were examined within each stratum. The 6-h window was selected for consistency with earlier studies (3) and because it has been suggested that cTnT drawn 6 to 


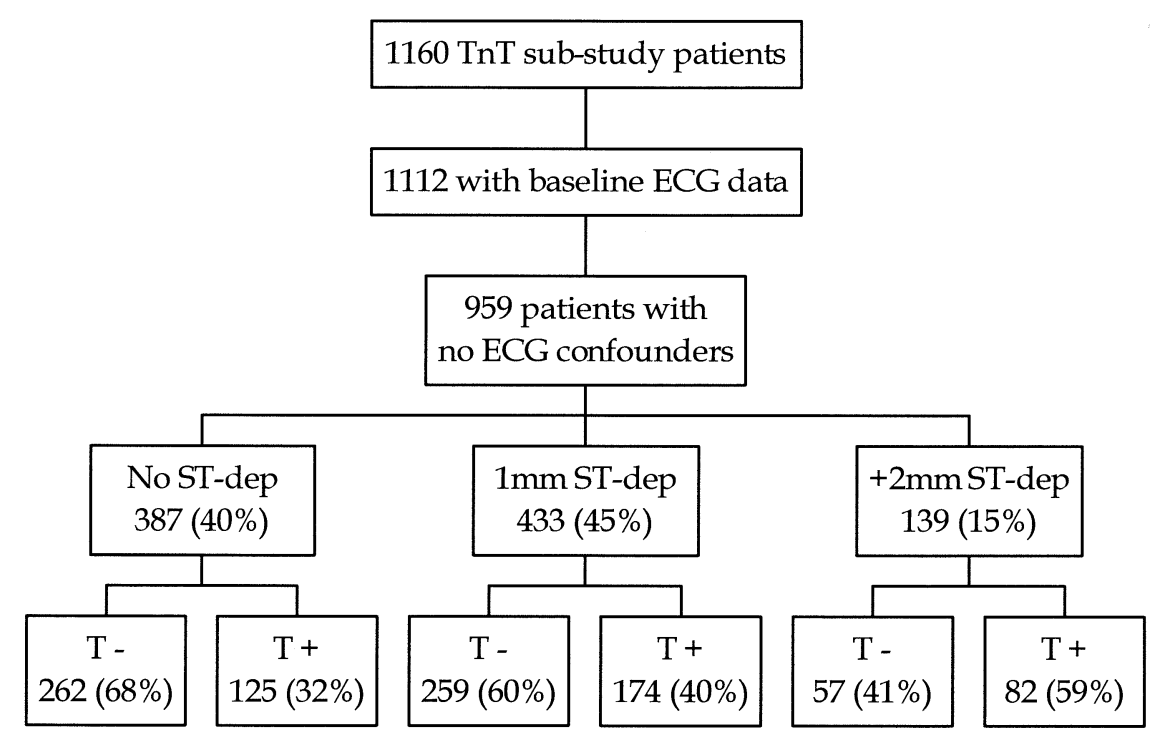

Figure 1. Description of the patient population. $\mathrm{ECG}=$ electrocardiogram; ST-dep $=\mathrm{ST}$-segment depression; $\mathrm{TnT}=\operatorname{troponin}$; $\mathrm{T}-=\operatorname{troponin} \mathrm{negative}$; $\mathrm{T}+=$ Troponin positive.

$12 \mathrm{~h}$ after symptom onset is optimum in risk stratification (20).

Statistical analyses. Chi-square tests (for categorical variables) and the nonparametric Kruskal-Wallis tests (for continuous variables) were used to compare characteristics across groups of patients. Kaplan-Meier analysis was used to study the relationship between the magnitude of ST $\downarrow$ and cTnT positivity and six-month death/(re)MI rates. Survival curves were compared using the log-rank test statistic.

The univariate associations between ST $\downarrow$ categories and $c \operatorname{TnT}$ status and adverse outcomes were measured using both chi-squared tests and logistic regression analysis. Transformations of the continuous cTnT variable were considered to better examine its relationship with long-term outcomes.

A multivariable logistic regression model was developed to assess the combined prognostic value of positive cTnT and ST $\downarrow$ categories in predicting six-month death or (re)MI. Univariate analyses of baseline variables were followed by a backward stepwise variable selection procedure. The magnitude of ST $\downarrow(0,1$, and $2 \mathrm{~mm})$ was included as a categorical variable. The $\mathrm{c} \operatorname{Tn} \mathrm{T}$ variable was included as a continuous variable, a dichotomous variable (with values above $0.1 \mathrm{ng} / \mathrm{ml}$ being assigned a value of 1 ), as well as a categorical variable (using quartiles as cut points). The overall performance of the final model was assessed using the c-index. The 95\% CI around the estimate (i.e., the interval within which we can say with $95 \%$ probability that the true c-index value is contained) was also calculated. The c-index is a measure of model discrimination: the extent to which the model predicts higher probabilities of outcome for patients who have the outcome and is equal to the area under the receiver operating characteristic curve (21).

\section{RESULTS}

Baseline ECG data were available for 1,112 (96\%) of the 1,160 patients enrolled in the PARAGON-B troponin T substudy (Fig. 1). There were no differences in baseline characteristics or outcomes, other than a higher rate of previous MI ( $46 \%$ vs. $31 \%$; $p=0.04)$ and prior coronary artery bypass graft ( $19 \%$ vs. $10 \%$; $=0.05)$, between the 48 patients with no ECG data and those with ECG data. Among the 1,112 patients with ECG data, 153 (14\%) had ECG confounders and were excluded from the analyses. Patients with ECG confounders were significantly older and had higher frequency of risk factors such as prior heart failure, hypertension, and diabetes. Six-month mortality/ (re)MI rate among patients with ECG confounders was $15 \%$ and $42 \%$ of these patients were classified as troponin positive.

After excluding patients with ECG confounding factors, the final study population consisted of 959 patients: 387 (40\%) had no ST $\downarrow$; 433 (45\%) had ST $\downarrow$ of $1 \mathrm{~mm}$ in two contiguous leads; and 139 (15\%) had ST $\downarrow$ of $\geq 2 \mathrm{~mm}$ in two contiguous leads. Based on a definition of $\geq 0.1 \mathrm{ng} / \mathrm{ml}$ used in the cTnT substudy, $381(40 \%)$ were classified as cTnT-positive.

Baseline characteristics of the patient population according to ST $\downarrow$ categories are presented in Table 1 . Patients with ST $\downarrow \geq 2 \mathrm{~mm}$ were older, more likely male, and less likely to have undergone prior percutaneous coronary intervention. These patients had significantly higher rates of hypertension, prior MI, prior angina, peripheral vascular disease, and history of congestive heart failure. Extent of ST $\downarrow$ and cTnT-positivity were positively correlated (Pearson correlation coefficient $=0.17, \mathrm{p}<0.01$ ): patients with $\mathrm{ST} \downarrow \geq 2 \mathrm{~mm}$ had the highest median cTnT levels (0.15 $\mathrm{ng} / \mathrm{ml}$, interquartile range [IQR]: $0.02,0.49)$ compared 
Table 1. Baseline Characteristics of PARAGON-B Patients by ST $\downarrow$ Categories

\begin{tabular}{|c|c|c|c|c|}
\hline Characteristics & No ST $\downarrow$ & $\mathrm{ST} \downarrow=1 \mathrm{~mm}$ & $\mathrm{ST} \downarrow \geq 2 \mathrm{~mm}$ & p Value \\
\hline Sample size & 387 & 433 & 139 & \\
\hline $\mathrm{Age}^{*}$ & $61(51,68)$ & $65(55,73)$ & $69(61,74)$ & $<0.01$ \\
\hline Female & 35.1 & 42.0 & 28.8 & 0.01 \\
\hline Race (Caucasian) & 89.1 & 95.4 & 95.7 & $<0.01$ \\
\hline Heart rate* & $71(61,82)$ & $76(65,87)$ & $83(74,94)$ & $<0.01$ \\
\hline Systolic BP* & $135(120,152)$ & $140(124,160)$ & $140(130,165)$ & $<0.01$ \\
\hline Diastolic BP* & $80(70,90)$ & $80(76,90)$ & $85(80,92)$ & $<0.01$ \\
\hline Family history of CHD & 46.4 & 37.0 & 34.8 & $<0.01$ \\
\hline Prior heart failure & 7.2 & 8.8 & 15.8 & 0.01 \\
\hline Hypertension & 53.2 & 53.6 & 67.6 & $<0.01$ \\
\hline Hypercholesterolemia & 44.2 & 45.4 & 46.8 & 0.86 \\
\hline Prior angina & 65.4 & 66.5 & 79.9 & $<0.01$ \\
\hline Diabetes & 17.6 & 20.8 & 23.0 & 0.30 \\
\hline Smoking & & & & $<0.01$ \\
\hline Never & 35.4 & 42.5 & 40.3 & \\
\hline Past & 29.7 & 31.6 & 38.1 & \\
\hline Current & 34.4 & 25.9 & 21.6 & \\
\hline Stroke & 3.9 & 3.2 & 4.3 & 0.80 \\
\hline TIA & 1.6 & 3.5 & 2.9 & 0.22 \\
\hline Previous MI & 26.4 & 27.5 & 41.7 & $<0.01$ \\
\hline Prior angio & 30.5 & 25.6 & 20.9 & 0.07 \\
\hline Prior PTCA & 14.2 & 10.9 & 6.5 & 0.04 \\
\hline Prior CABG & 10.1 & 9.5 & 5.8 & 0.31 \\
\hline Severe COPD & 4.9 & 4.4 & 4.3 & 0.93 \\
\hline Cancer & 3.6 & 2.1 & 1.4 & 0.25 \\
\hline CRF & 0.8 & 0.9 & 2.9 & 0.12 \\
\hline PVD & 5.4 & 7.6 & 12.9 & 0.02 \\
\hline Arrhythmias & 9.6 & 11.1 & 17.3 & 0.05 \\
\hline Enroll MI & 30.2 & 32.6 & 38.8 & 0.10 \\
\hline \multicolumn{5}{|l|}{ Troponin } \\
\hline Troponin + & 32.3 & 40.2 & 59.0 & $<0.01$ \\
\hline Troponin measure* & $0.03(0.0,0.21)$ & $0.05(0.0,0.29)$ & $0.15(0.02,0.49)$ & $<0.01$ \\
\hline
\end{tabular}

*Values presented are medians and interquartile range.

$\mathrm{BP}=$ blood pressure; $\mathrm{CABG}=$ coronary artery bypass surgery; $\mathrm{CHD}=$ coronary heart disease; $\mathrm{COPD}=$ chronic obstructive pulmonary disease; $\mathrm{CRF}=$ chronic renal failure; $\mathrm{MI}=$ myocardial infarction; PARAGON $=$ platelet IIb/IIIa Antagonism for the Reduction of Acute coronary syndrome events in a Global Organization Network trial; PTCA = percutaneous transluminal coronary angioplasty; PVD $=$ peripheral vascular disease; ST $\downarrow=$ ST-segment depression; TIA $=$ transient ischemic attack.

with median values of $0.05 \mathrm{ng} / \mathrm{ml}$ (IQR: $0.0,0.29)$ among patients with ST $\downarrow$ of $1 \mathrm{~mm}$ and $0.03 \mathrm{ng} / \mathrm{ml}$ (IQR: 0.0 , 0.21 ) among patients with no ST $\downarrow$ ( $\mathrm{p}<0.01$ ).

Prognostic significance of ST-segment depression on baseline ECG. Adverse outcomes by ST $\downarrow$ categories are presented in Table 2. At six months, the (re)MI rate among patients with ST $\downarrow \geq 2 \mathrm{~mm}$ (16.7\%) was almost twice that

Table 2. Outcomes by ST $\downarrow$ category

\begin{tabular}{lcccr}
\hline \multicolumn{1}{c}{ Characteristics } & No ST $\downarrow$ & $\mathbf{S T} \downarrow \mathbf{~ = ~} \mathbf{~ m m}$ & $\mathbf{S T} \downarrow \geq \mathbf{2} \mathbf{~ m m}$ & $\begin{array}{c}\mathbf{p} \\
\text { Value }\end{array}$ \\
\hline Sample size & 387 & 433 & 139 & \\
Death 48 h & 0.0 & 0.5 & 1.4 & 0.08 \\
Death 30 day & 0.8 & 3.2 & 5.0 & $<0.01$ \\
Death 6 month & 1.8 & 6.1 & 10.1 & $<0.01$ \\
MI 48 h & 2.1 & 2.8 & 4.3 & 0.37 \\
MI 30 day & 8.0 & 11.6 & 14.4 & 0.07 \\
MI 6 month & 8.6 & 11.8 & 16.7 & 0.03 \\
Death/MI 48 h & 2.1 & 3.2 & 5.8 & 0.10 \\
Death/MI 30 day & 8.3 & 12.9 & 17.3 & 0.01 \\
Death/MI 6 month & 9.8 & 14.5 & 22.3 & 0.01 \\
\hline
\end{tabular}

Abbreviations as in Table 1. of patients with no ST $\downarrow$ (8.6\%). In addition, the mortality rate among patients with ST $\downarrow \geq 2 \mathrm{~mm}$ was $10.1 \%$ compared with $1.8 \%$ among patients with no ST $\downarrow$. Figure $2 \mathrm{~A}$ shows the Kaplan-Meier six-month death/(re)MI curves for the three ST $\downarrow$ subgroups. Survival free of (re)MI among patients with no ST $\downarrow$ was significantly higher compared with those with ST $\downarrow$ of $1 \mathrm{~mm}$ (log-rank statistic $=4.2 ; \mathrm{p}$ $=0.04)$ and ST $\downarrow \geq 2 \mathrm{~mm}(\log$-rank statistic $=14.2 ; \mathrm{p}<$ $0.01)$. Similarly, the difference in survival between patients with $1 \mathrm{~mm} \mathrm{ST} \downarrow$ was significantly higher than that of patients with $2 \mathrm{~mm} \mathrm{ST} \downarrow$ (log-rank statistic $=4.6$; p $=$ 0.03).

Prognostic significance of troponin measures. The $\mathrm{cTnT}$ measurements ranged from 0.0 to $8.37 \mathrm{ng} / \mathrm{ml}$ in this population. In Table 3 and Figure 2B we present adverse outcomes by cTnT status using the PARAGON-B tropo$\operatorname{nin} \mathrm{T}$ substudy definition of $\geq 0.1 \mathrm{ng} / \mathrm{ml}$ considered cTnTpositive. Six-month (re)MI-free survival among cTnTpositive patients was significantly lower than that of cTnTnegative patients (log-rank statistic $=10.24 ; \mathrm{p}<0.01)$.

We further explored the relationship between continuous 
A

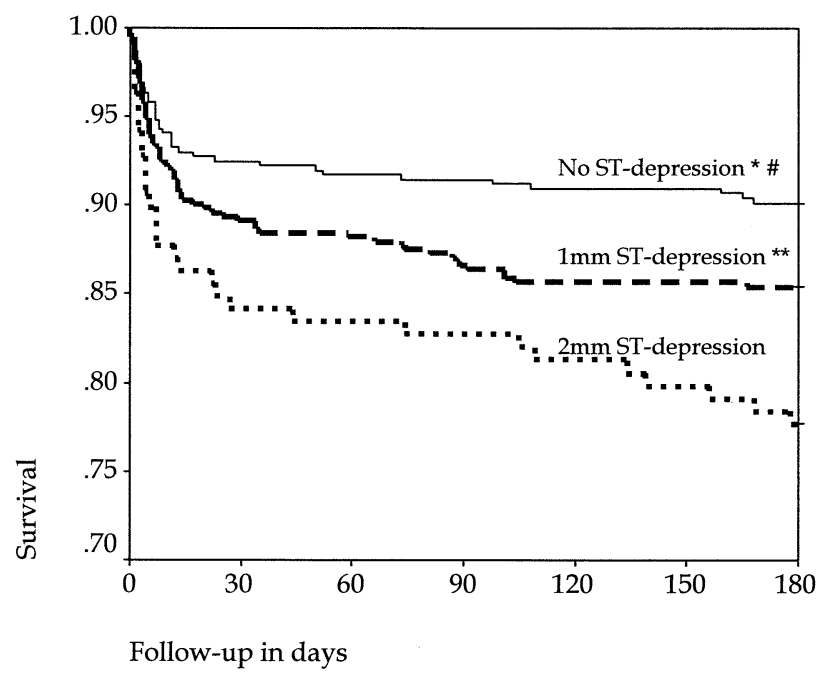

Troponin T and ST-Segment Depression in ACS

B

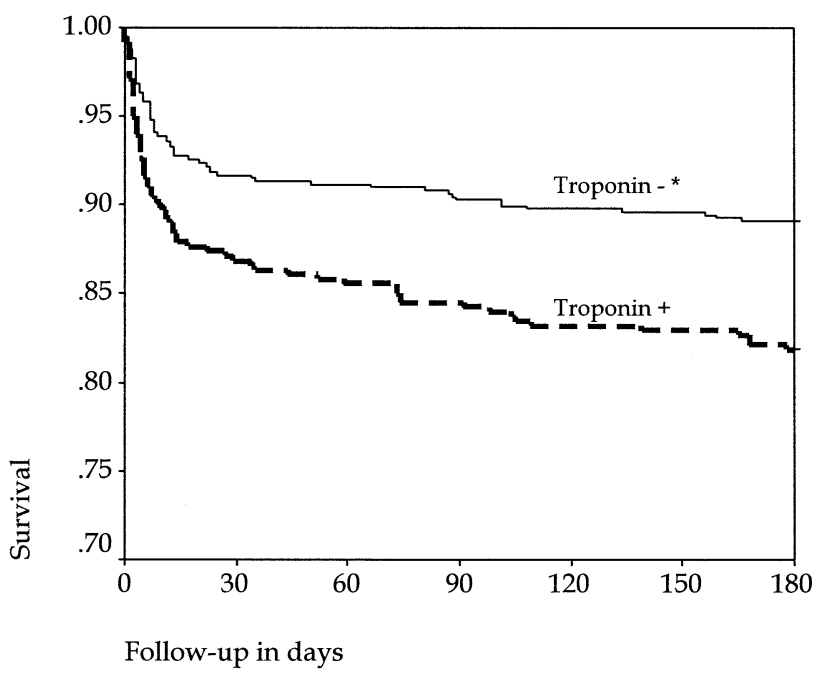

Figure 2. Kaplan-Meier curves of six-month survival free of death/(re)myocardial infarction. (A) Categorized by ST-segment depression categories. *Log rank statistics $(0$ vs. $1 \mathrm{~mm})=4.2(\mathrm{p}=0.04)$. \#Log rank statistic $(0$ vs. $2 \mathrm{~mm})=14.2(\mathrm{p}<0.01) .{ }^{* * *} \mathrm{Log}$ rank statistic $(1 \mathrm{vs} .2 \mathrm{~mm})=4.6(\mathrm{p}=0.03)$. (B) Categorized by troponin status. ${ }^{*} \log$ rank statistics $=10.24(\mathrm{p}<0.01)$.

cTn $\mathrm{T}$ values and long-term outcomes by considering several transformations. Figure 3 shows six-month rates of death/ (re)MI by cTnT quartiles. The categorization of all patients with no troponin elevation $(0.0 \mathrm{ng} / \mathrm{ml})$ in the first quartile resulted in an unequal distribution of patients in the first and second quartile. Overall, 365 patients with a cTnT level of $0.0 \mathrm{ng} / \mathrm{ml}$ cTnT were categorized as the first quartile; patients with cTnT levels between 0.01 and $0.047 \mathrm{ng} / \mathrm{ml}$ were categorized as second $(n=113)$; from 0.048 to 0.277 as third $(\mathrm{n}=241)$; and all cTnT levels $>0.278 \mathrm{ng} / \mathrm{ml}$ were included in the fourth quartile $(\mathrm{n}=240)$. Death/(re)MI rates ranged from $6.3 \%$ in the first cTnT quartile to $20.8 \%$ in the fourth quartile (chi-squared test for trend $=30.6 ; \mathrm{p}$ $<0.001)$. The biggest increment in adverse event rate was seen between the first two quartiles (from 6.3\% to 14.2\%). Prognostic significance of combining ECG and cTnT data. Figure 4 shows the six-month death/(re)MI rates by $\mathrm{ST} \downarrow$ and $\mathrm{cTnT}$ status (positive $\geq 0.1 \mathrm{ng} / \mathrm{ml}$ ). Rates ranged from $8.4 \%$ among patients with no ST $\downarrow$ and negative cTnT to $26.8 \%$ among patients with ST $\downarrow \geq 2 \mathrm{~mm}$ and positive cTnT. Within each ST $\downarrow$ category positive cTnT was associated with higher risk; however, these differences

Table 3. Outcomes by Troponin Status

\begin{tabular}{lccr}
\hline \multicolumn{1}{c}{ Characteristics } & Troponin - & Troponin & p Value \\
\hline Sample size & 578 & 381 & \\
Death 48 h & 0.2 & 0.8 & 0.31 \\
Death 30 day & 1.7 & 3.7 & 0.09 \\
Death 6 month & 3.3 & 7.4 & $<0.01$ \\
MI 48 h & 1.6 & 4.5 & $<0.01$ \\
MI 30 day & 9.0 & 12.9 & 0.07 \\
MI 6 month & 9.7 & 13.6 & 0.07 \\
Death/MI 48 h & 1.7 & 5.2 & $<0.01$ \\
Death/MI 30 day & 9.5 & 15.0 & 0.01 \\
Death/MI 6 month & 10.9 & 18.1 & $<0.01$ \\
\hline
\end{tabular}

Abbreviations as in Table 1. did not reach statistical significance. The difference was most pronounced among patients with ST $\downarrow \geq 2 \mathrm{~mm}$ (15.8\% among cTnT-negative vs. $26.8 \%$ among cTnTpositive, $\mathrm{p}=0.15$ ).

Table 4 shows the univariate and multivariable association between baseline variables and six-month death/ (re)MI. Individually, both ST $\downarrow$ and cTnT (irrespective of categorization) were significant predictors of adverse outcomes (see univariate ORs column in Table 4). Odds ratios associated with a unit change in $\mathrm{cTnT}$ are difficult to interpret clinically and given our finding that quartiles were a more sensitive marker of risk compared with the dichotomous cTnT variable, cTnT quartiles were used in the multivariable analysis. After adjusting for other baseline factors, both ST $\downarrow$ and cTnT remained prognostically significant. Patients with ST $\downarrow \geq 2 \mathrm{~mm}$ were twice as likely to experience an adverse outcome compared with patients with no ST $\downarrow$ (OR 1.91; 95\% CI: 1.10 to 3.32) while patients with cTnT levels higher than $0.278 \mathrm{ng} / \mathrm{ml}$ had approximately four times the likelihood of death or (re)MI compared with patients with no cTnT elevation (OR 3.86; 95\% CI: 2.24 to 6.66). Other significant predictors included prior percutaneous coronary intervention, peripheral vascular disease, and increasing age. The c-statistic for the model was 0.70 (95\% CI: 0.65 to 0.75$)$ indicating that the model had a moderately good ability to discriminate between patients who did and did not experience the outcome.

Treatment effect. Treatment effects according to ST $\downarrow$ and $\mathrm{c} T n \mathrm{~T}$ status are presented in Tables 5 and 6 . In general, patients treated with lamifiban had lower adverse event rates compared to patients in the placebo arm across ST $\downarrow$ categories; however, these differences did not reach statistical significance. The significant reduction in (re)MI events among cTnT-positive patients treated with lamifiban ob- 


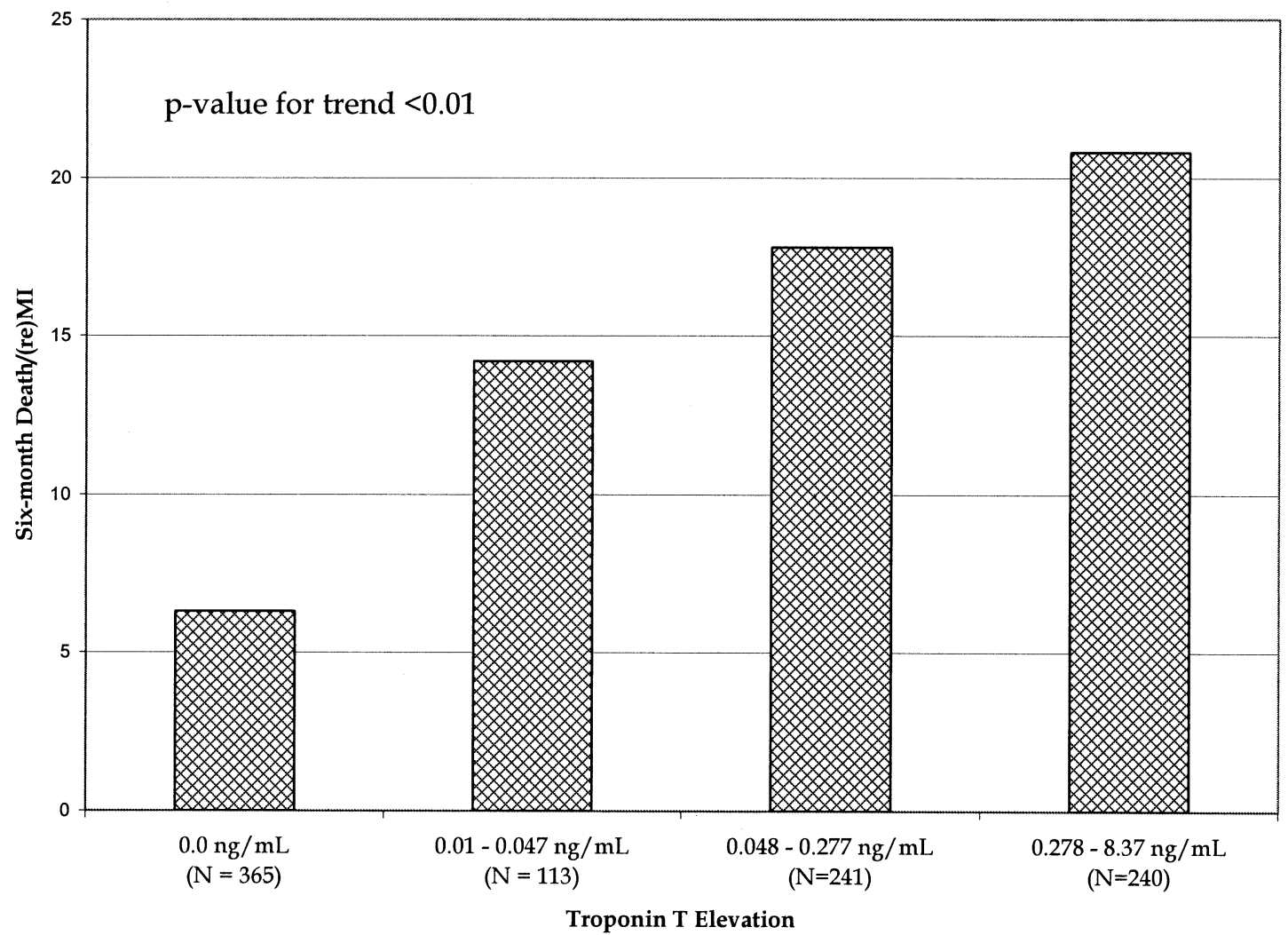

Figure 3. Six-month death/(re)myocardial infarction (MI) rates by troponin quartiles.

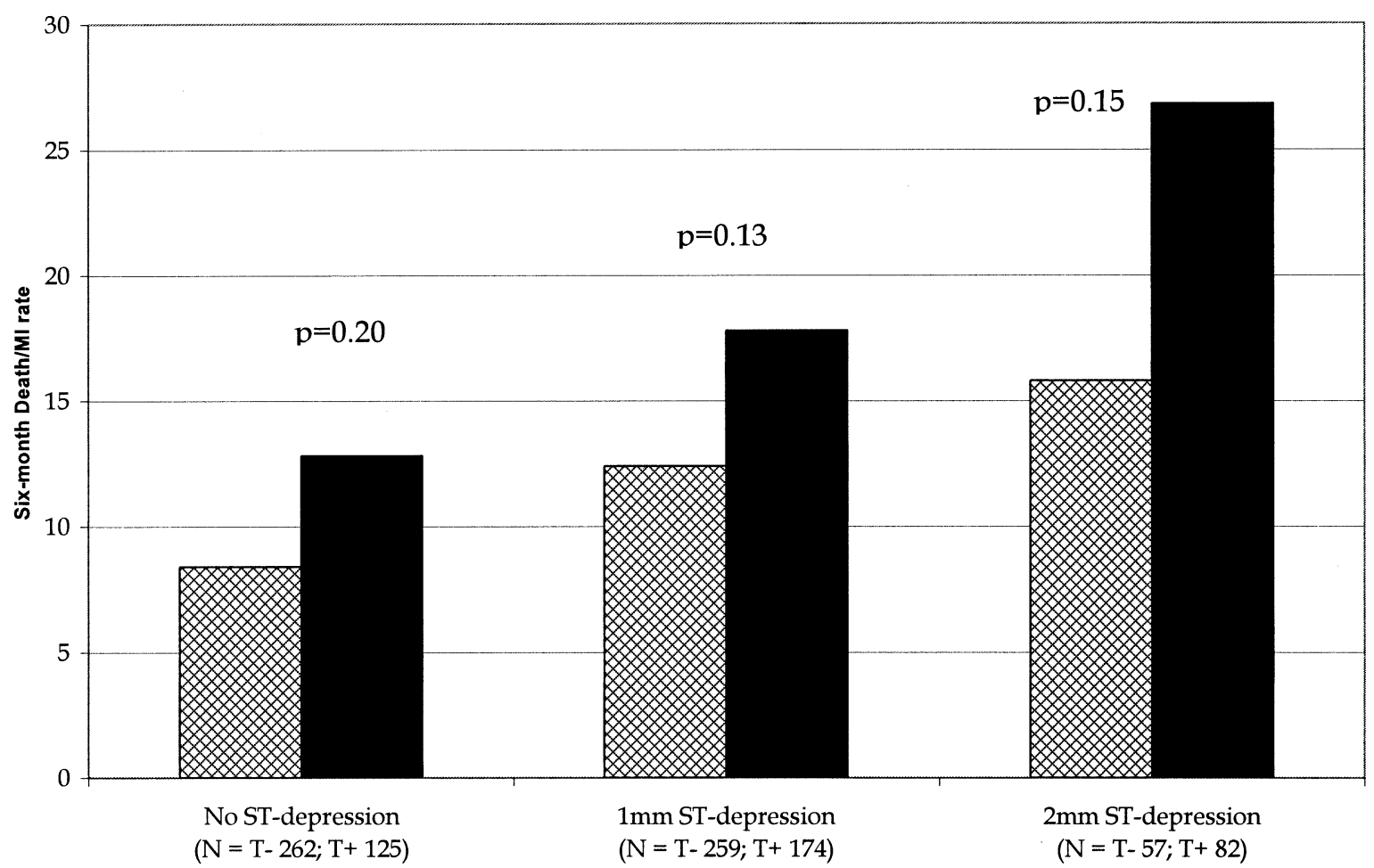

Figure 4. Six-month death/(re)myocardial infarction (MI) rates by ST-segment depression categories and troponin status. Shaded square $=$ troponin closed square $=$ troponin + . 
Table 4. Univariate and Multivariable Associations-Death/MI 6 Months

\begin{tabular}{|c|c|c|c|c|c|c|}
\hline \multirow[b]{2}{*}{ Variable } & \multicolumn{3}{|c|}{ Univariate Associations } & \multicolumn{3}{|c|}{ Multivariable Associations* } \\
\hline & OR & Lower CI & Upper CI & OR & Lower CI & Upper CI \\
\hline Age (10 yr increments) & 1.25 & 1.16 & 1.36 & 1.15 & 1.05 & 1.26 \\
\hline Gender & 0.92 & 0.63 & 1.35 & & & \\
\hline Diastolic blood pressure & 1.00 & 0.99 & 1.01 & & & \\
\hline Systolic blood pressure & 1.00 & 1.00 & 1.01 & & & \\
\hline Heart rate & 1.00 & 0.99 & 1.01 & & & \\
\hline Hypertension & 1.10 & 0.76 & 1.60 & & & \\
\hline Diabetes & 1.64 & 1.08 & 2.50 & & & \\
\hline Hyperlipidemia & 1.30 & 0.90 & 1.88 & & & \\
\hline Family history of CHD & 1.11 & 0.77 & 1.62 & & & \\
\hline Previous MI & 1.33 & 0.90 & 1.96 & & & \\
\hline Previous angina & 1.42 & 0.94 & 2.15 & & & \\
\hline Prior PTCA & 1.66 & 1.00 & 2.76 & 1.86 & 1.09 & 3.16 \\
\hline Prior CABG & 1.21 & 0.66 & 2.21 & & & \\
\hline Severe COPD & 2.19 & 1.08 & 4.44 & & & \\
\hline Cancer & 1.20 & 0.41 & 3.55 & & & \\
\hline Peripheral vascular disease & 2.66 & 1.53 & 4.62 & 2.32 & 1.29 & 4.17 \\
\hline Congestive heart failure & 1.50 & 0.89 & 2.53 & & & \\
\hline Stroke/TIA & 2.04 & 1.07 & 3.92 & & & \\
\hline \multicolumn{7}{|l|}{ Smoking } \\
\hline Past & 1.49 & 0.96 & 2.31 & & & \\
\hline Current & 1.31 & 0.83 & 2.08 & & & \\
\hline \multicolumn{7}{|l|}{ ST-segment depression } \\
\hline $1 \mathrm{~mm}$ & 1.56 & 1.02 & 2.40 & 1.34 & 0.86 & 2.09 \\
\hline $2 \mathrm{~mm}$ & 2.64 & 1.57 & 4.44 & 1.91 & 1.10 & 3.32 \\
\hline \multicolumn{7}{|l|}{ Troponin $† \neq$} \\
\hline $0.01-0.047 \mathrm{ng} / \mathrm{ml}$ & 2.45 & 1.25 & 4.82 & 2.43 & 1.22 & 4.85 \\
\hline $0.048-0.277 \mathrm{ng} / \mathrm{ml}$ & 3.23 & 1.89 & 5.16 & 3.18 & 1.83 & 5.53 \\
\hline $0.278-8.37 \mathrm{ng} / \mathrm{ml}$ & 3.91 & 2.32 & 6.61 & 3.86 & 2.24 & 6.66 \\
\hline
\end{tabular}

served at 30 days persisted at 6 months. However, as documented in the main PARAGON-B troponin substudy paper, there was no significant treatment difference in the six-month composite death/(re)MI rates (7). Overall, treatment with lamifiban did not have a significant impact on six-month death/(re)MI rates either in the univariate or in the multivariable context.

Time effect. Table 7 describes the impact of time to evaluation on the relationship between the markers and six-month death/(re)MI. The median time to ECG was $1.7 \mathrm{~h}$ (IQR: $0.2,4.1$ ) and the median time to $\mathrm{cTnT}$ was $6.8 \mathrm{~h}$ (IQR: 4.0, 10.2). The ECGs were done within $6 \mathrm{~h}$ of symptom onset in $743(78 \%)$ of patients enrolled in the study and after $6 \mathrm{~h}$ in $144(15 \%)$ patients. The frequency of $\mathrm{ST} \downarrow \geq 2 \mathrm{~mm}$ was lower in the latter group (8\% vs. $16 \%$; $\mathrm{p}$ $=0.02)$; however, its presence was associated with a far greater risk of six-month death/(re)MI (OR of 7.3 compared to 2.1).

With respect to $\mathrm{cTnT}$, a majority of the patients $(\mathrm{n}=532$, $56 \%)$ had their $\mathrm{cTnT}$ drawn after $6 \mathrm{~h}$ of symptom onset. However, the presence of elevated $\mathrm{c} T \mathrm{nT}(\geq 0.1 \mathrm{ng} / \mathrm{ml})$ within $6 \mathrm{~h}$ of symptom onset was associated with higher risk of adverse outcome than the presence of elevated cTnT after $6 \mathrm{~h}$ (OR 2.4; 95\% CI: 1.4, 4.2 vs. OR 1.5; 95\% CI: 0.92, 2.5).

Table 5. Treatment Effect by ST $\downarrow$ Status

\begin{tabular}{|c|c|c|c|c|c|c|}
\hline \multirow{2}{*}{$\begin{array}{c}\text { Characteristics } \\
\text { Treatment }\end{array}$} & \multicolumn{2}{|c|}{ No ST $\downarrow$} & \multicolumn{2}{|c|}{$\mathrm{ST} \downarrow=1 \mathrm{~mm}$} & \multicolumn{2}{|c|}{$\mathrm{ST} \downarrow \geq 2 \mathrm{~mm}$} \\
\hline & $\mathbf{R x}$ & Placebo & $\mathbf{R x}$ & Placebo & $\mathbf{R x}$ & Placebo \\
\hline Sample size & 190 & 197 & 226 & 207 & 64 & 75 \\
\hline Death 30 day & 0.0 & 1.5 & 3.1 & 3.4 & 4.7 & 5.3 \\
\hline Death 6 month & 1.1 & 2.6 & 6.7 & 5.4 & 9.5 & 10.7 \\
\hline MI 30 day & 6.3 & 9.6 & 9.8 & 13.6 & 14.1 & 14.7 \\
\hline MI 6 month & 6.5 & 10.7 & 10.4 & 13.3 & 15.9 & 17.3 \\
\hline Death/MI 30 day & 6.3 & 10.2 & 11.5 & 14.5 & 17.2 & 17.3 \\
\hline Death/MI 6 month & 7.4 & 12.2 & 13.7 & 15.5 & 21.9 & 22.7 \\
\hline
\end{tabular}

Abbreviations as in Table 1. 
Table 6. Treatment Effect by Troponin Status

\begin{tabular}{lrrrrrr}
\hline \multirow{2}{*}{$\begin{array}{c}\text { Characteristics } \\
\text { Treatment }\end{array}$} & \multicolumn{2}{c}{ cTnT } & & \multicolumn{2}{c}{ cTnT+ } \\
\cline { 2 - 3 } \cline { 5 - 6 } & $\mathbf{R x}$ & Placebo & & Rx & Placebo \\
\hline Sample size & 290 & 288 & & 190 & 191 \\
Death 30 day & 1.4 & 2.1 & & 3.2 & 4.2 \\
Death 6 month & 2.8 & 3.8 & & 8.0 & 6.9 \\
MI 30 day & 9.3 & 8.7 & & 8.5 & $17.3^{*}$ \\
MI 6 month & 9.9 & 9.5 & & 9.1 & $18.0^{*}$ \\
Death/MI 30 day & 9.7 & 9.4 & & 11.1 & $18.8 \dagger$ \\
Death/MI 6 month & 10.3 & 11.5 & & 15.3 & 20.9 \\
\hline
\end{tabular}

*Treatment groups are statistically significantly different at $\mathrm{p}<0.01$ level; †treatment group comparison $\mathrm{p}=0.04$.

Abbreviations as in Table 1.

\section{DISCUSSION}

Our study documents the complementary role of baseline quantitative $\mathrm{ST} \downarrow$ and $\mathrm{cTnT}$ measurement in riskstratifying non-ST-segment elevation ACS patients. In combination, the markers appear to provide an integrated and improved delineation of the spectrum of ACS risk: with the lowest rates of adverse outcomes being observed in cTnT-negative patients with no ST $\downarrow$ (8.4\%) and the highest rates being observed in cTnT-positive patients with $\mathrm{ST} \downarrow \geq 2 \mathrm{~mm}$ (26.8\%). In a multivariable logistic regression model, both markers were found to be independent predictors. Compared to patients with no ST $\downarrow$, there was a trend towards a higher six-month death/(re)MI rate among patients with $1 \mathrm{~mm} \mathrm{ST} \downarrow$ (OR 1.34; 95\% CI: 0.86, 2.09); and a significant increase in the rate among patients with ST $\downarrow$ $\geq 2 \mathrm{~mm}$ (OR 1.91; 95\% CI: 1.10, 3.32). Patients with cTnT levels higher than $0.278 \mathrm{ng} / \mathrm{ml}$ had approximately four times the likelihood of an adverse event compared with patients with no cTnT elevation (OR 3.86; 95\% CI: 2.24, 6.66).

Our study has several interesting secondary findings. First, our results underscore the prognostic importance of lower levels of cTnT. The PARAGON-B troponin T substudy defined positivity as $\geq 0.1 \mathrm{ng} / \mathrm{ml}$; however, in examining the relationship between continuous cTnT and six-month outcomes, we found this dichotomization may be less than optimal for risk stratification. Patients with cTnT levels in the range of 0.01 to $0.047 \mathrm{ng} / \mathrm{ml}$ had six-month death/(re)MI rates of $14.2 \%$ compared with $6.3 \%$ among patients with no detectable cTnT. Our results are consistent with those reported recently by Lindhal et al. (6). In the Fast Revascularization during Instability in Coronary artery disease (FRISC-II) substudy, any detectable elevation of $\mathrm{cTnT}$ was associated with higher risk of (re)MI or death at one year. One limitation of using lower cTnT cutoffs is the greater variability and loss in precision. Typical analytical performance of the c $\operatorname{TnT}$ assay used in the current study is characterized by a precision (CV) of about $20 \%$ at 0.01 $\mathrm{ng} / \mathrm{ml}$, the 99 th percentile for a reference control population ( $95 \%$ CI: 0.006 to 0.014 ). The precision (CV) at $0.03 \mathrm{ng} / \mathrm{ml}$ achieves $10 \%$ (95\% CI: 0.024 to 0.036$)$; at cTnT concentrations $>0.05 \mathrm{ng} / \mathrm{ml}$ the precision $(\mathrm{CV})$ is constant at $5 \%$ to $8 \%$ (data on file at Roche Diagnostics).
Second, the time from symptom onset to evaluation appears to have a significant impact on the prognostic value of the markers. Patients with ST $\downarrow \geq 2 \mathrm{~mm}$ after $6 \mathrm{~h}$ of symptom onset had more than three times the risk of six-month death/(re)MI compared with patients with ST $\downarrow$ $\geq 2 \mathrm{~mm}$ on ECGs done within $6 \mathrm{~h}$ (OR 7.3 vs. 2.1). Worse outcomes with persistent ST $\downarrow$ may be indicative of worse myocardial ischemia and/or more extensive or severe coronary artery disease. Given the potential prognostic implications, further exploration of the temporal evolution of ST-segment changes is warranted.

In contrast, earlier elevations of cTnT appear to be markers of higher risk. A possible explanation is that early elevations of troponin are indicators of higher risk patients with active lesions and "stuttering" courses of intermittent occlusion and reperfusion preceding their ultimate presentation for medical attention. This hypothesis is supported, in part, by the higher frequency of cardiac symptoms among these patients in the two weeks prior to study enrollment (80\% vs. 69\%) (Table 7). Our results are consistent with those from the Thrombolysis In Myocardial Infarction (TIMI)-IIIb troponin I analysis in which patients enrolled within $6 \mathrm{~h}$ of symptom onset who had elevated troponin I levels had a 42-day mortality rate of $3.1 \%$ compared with $1.7 \%$ among patients without early troponin I elevations (3). In our study, the corresponding 30-day mortality rates were $3.9 \%$ among cTnT-positive and 1.4\% among cTnTnegative patients. While the TIMI-IIIb result among patients presenting after $6 \mathrm{~h}$ of symptom onset appears inconsistent with our findings (42-day mortality risk ratio of 9.5 between troponin I positive and negative patients), this result is driven by the extremely low-risk of troponin I negative patients ( $0.4 \%$ mortality compared with $4.0 \%$ among troponin I positive patients). Among corresponding patients in our study, 30-day mortality rate in cTnTpositive patients was similar to those of the TIMI-IIIb cohort (3.6\%) but was much higher among cTnT-negative patients $(2.1 \%)$ resulting in a lower risk ratio.

Third, our study shows that cTnT is superior to ST $\downarrow$ in assisting treatment decisions, especially in the short-term. Among cTnT-positive patients, treatment with a GP IIb/ IIIa inhibitor (lamifiban) significantly reduced the risk of both (re)MI (8.5 vs. $17.3, \mathrm{p}<0.01)$ and the composite outcome of death/(re)MI (11.1 vs. $18.8, \mathrm{p}=0.04)$ in the short term and of (re)MI alone at six months ( 9.1 vs. 18.0, $\mathrm{p}<0.01)$. Although death/(re)MI rates were consistently lower among patients treated with lamifiban compared with placebo across all ST-depression categories, the differences did not reach statistical significance. Therefore, while the presence of ST-segment changes at baseline may have important prognostic information with respect to coronary revascularization $(22,23)$, they may offer less guidance with respect to pharmacotherapy.

Two issues associated with the current study must be noted. First, an analysis examining the combined value of baseline ECG and troponins with respect to response to 
Table 7. Examining the Impact of Time to ECG and Time to cTnT on Their Prognostic Significance

\begin{tabular}{|c|c|c|}
\hline $\mathrm{ST} \downarrow$ & $\begin{array}{c}\text { Time From Onset of } \\
\text { Symptoms to ECG }<6 \mathrm{~h}\end{array}$ & $\begin{array}{c}\text { Time From Onset of } \\
\text { Symptoms to ECG }>6 \mathrm{~h}\end{array}$ \\
\hline Number of patients & 743 & 144 \\
\hline \multicolumn{3}{|l|}{ Distribution of ST $\downarrow$} \\
\hline No ST $\downarrow$ & $281(38 \%)$ & $69(48 \%)$ \\
\hline $1 \mathrm{~mm} \mathrm{ST} \downarrow$ & $344(46 \%)$ & $63(44 \%)$ \\
\hline $\mathrm{ST} \downarrow \geq 2 \mathrm{~mm}$ & $118(16 \%)$ & $12(8 \%)$ \\
\hline \multicolumn{3}{|l|}{$\begin{array}{l}\text { Association with outcomes } \\
\text { (OR for 6-Month death/MI) }\end{array}$} \\
\hline $1 \mathrm{~mm} \mathrm{ST} \downarrow$ & $1.2(0.8-2.0)$ & $4.2(1.1-15.9)$ \\
\hline $\mathrm{ST} \downarrow \geq 2 \mathrm{~mm}$ & $2.1(1.2-3.7)$ & $7.3(1.3-42.0)$ \\
\hline Duration of pain in min* & $30(20,120)$ & $210(38,618)$ \\
\hline Troponin & $\begin{array}{c}\text { Time From Onset of } \\
\text { Symptoms to Troponin }<6 \mathrm{~h}\end{array}$ & $\begin{array}{c}\text { Time From Onset of } \\
\text { Symptoms to Troponin }>6 \mathrm{~h}\end{array}$ \\
\hline Number of patients & 421 & 532 \\
\hline \multicolumn{3}{|l|}{ Distribution of troponin values } \\
\hline Negative & $294(70 \%)$ & $280(53 \%)$ \\
\hline Positive & $127(30 \%)$ & $252(47 \%)$ \\
\hline Continuous troponin* & $0.02(0,0.14)$ & $0.09(0,0.42)$ \\
\hline \multicolumn{3}{|l|}{$\begin{array}{l}\text { Association with outcomes } \\
\text { (OR for 6-month death/MI) }\end{array}$} \\
\hline Positive & $2.4(1.4,4.2)$ & $1.5(0.92-2.5)$ \\
\hline $\begin{array}{l}\text { Symptoms of MI/UA in the last } \\
2 \text { weeks }\end{array}$ & $80 \%$ & $69 \%$ \\
\hline Duration of pain in min* & $30(20,64)$ & $60(25,210)$ \\
\hline
\end{tabular}

treatment would be of interest; however, the small sample sizes in some of the groups limit the utility of such an analysis. Second, the cTnT and ST $\downarrow$ measures used in our analysis were analyzed in core laboratories and, therefore, were not available to investigators. However, the investigators had access to the ECGs and may have had access to local cTnT data, which may have influenced decisions regarding revascularization therapy. This in turn may have had an impact on outcomes. A preliminary analysis revealed no relationship between increasing ST $\downarrow$ and procedure use; however, cTnT-positive patients had a higher frequency of revascularization. We believe that these issues are beyond the scope of the current investigation and deserve further exploration.

Comparison with previous studies. Earlier studies examining the relative contributions of ST $\downarrow$ and cTnT positivity have focussed on short-term prognosis. Holmvang et al. (24) examined the combined value of ECG and biochemical assessment for very early risk stratification among patients with unstable coronary artery disease as part of the Thrombin Inhibition in Myocardial Ischemia (TRIM) substudy. Among 470 patients with readable ECGs, 64 (14\%) had $\mathrm{ST} \downarrow$ of at least $1 \mathrm{~mm}$ in any lead. In univariate analyses, both $\mathrm{ST} \downarrow$ and $\mathrm{cTnT} \geq 0.1 \mathrm{ng} / \mathrm{ml}$ were highly predictive of death/(re)MI within 30 days. Although in the multivariable context, cTnT did not provide additional prognostic information over and above that of ST $\downarrow$, it was effective in further risk-stratifying patients with no ST $\downarrow$ (30-day
death/[re]MI rates of $6 \%$ and $3 \%$ among c $\operatorname{Tn} \mathrm{T}$ positive and negative patients, respectively).

As part of the Fast Assessment of Thoracic Pain (FAST) study, Jernberg et al. (25) examined the combination of a continuous 12-lead ECG and cTnT status in patient risk-stratification. As in our study, cTnT positivity was defined as $>0.10 \mathrm{ng} / \mathrm{ml}$, however, ST $\downarrow$ was categorized into $\geq 0.05 \mathrm{mV}$ to $<0.10 \mathrm{mV}$ and $\geq 0.10 \mathrm{mV}$. In addition, ST episodes defined as a transient ST $\downarrow$ or elevations in any lead of at least $1 \mathrm{~mm}$ were identified. In a multivariable model, cTnT and ST episodes were independent predictors of 30-day death/(re)MI. Neither category of ST $\downarrow$ was found to be a statistically significant predictor of outcomes.

\section{CONCLUSIONS}

Our study documents that quantitative ST $\downarrow$ and cTnT status are complementary in assessing risk among ACS patients and that both should be employed to determine prognosis and assist in medical decision making. While both ST $\downarrow$ and cTnT are effective markers of risk, cTnT appears to be superior to ST $\downarrow$ in assisting decisions regarding the use of GP IIb/IIIa therapy. Furthermore, levels of cTnT lower than $0.1 \mathrm{ng} / \mathrm{ml}$ contain important prognostic information and should be incorporated into risk-assessment analysis. The relationship between cTnT and ST $\downarrow$ status and outcomes over a spectrum of times from symptom onset require further investigation. 
Reprint requests and correspondence: Dr. Paul W. Armstrong, 2-51 Medical Sciences Building, University of Alberta, Edmonton, Alberta T6G 2H7 Canada. E-mail: paul.armstrong@ ualberta.ca.

\section{REFERENCES}

1. Ohman EM, Armstrong PW, White HD, et al., for the GUSTOIII Investigators. Risk stratification with a point-of-care cardiac troponin $\mathrm{T}$ test in acute myocardial infarction. Am J Cardiol 1999;84:1281-6.

2. Ohman EM, Armstrong PW, Christenson RH, et al, for the GUSTO-IIa Investigators. Cardiac troponin T levels for risk stratification in acute myocardial infarction. N Engl J Med 1996;335:133341.

3. Antman EM, Tanasijevic MJ, Thompson B, et al. Cardiac-specific troponin I levels to predict the risk of mortality in patients with acute coronary syndromes. N Engl J Med 1996;335:1342-9.

4. Heeschen C, van den Brand MJ, Hamm CW, et al. Angiographic finding in patients with refractory unstable angina according to troponin T status. Circulation 1999;100:1509-14.

5. DeFillippi CR, Tocchi M, Parmar RJ, et al. Cardiac troponin T in chest pain unit patients without ischemic electrocardiographic changes: angiographic correlates and long-term clinical outcomes. J Am Coll Cardiol 2000;35:1827-34.

6. Lindahl B, Diderholm E, Lagerqvist B, Venge P, Wallentin L, and the FRISC-II Investigators. Mechanisms behind the prognostic value of troponin $\mathrm{T}$ in unstable coronary artery disease: a FRISC II substudy. J Am Coll Cardiol 2001;38:979-86.

7. Newby LK, Ohman EM, Christenson RH, et al. Benefit of glycoprotein IIb/IIIa inhibition in patients with acute coronary syndromes and troponin t-positive status: the PARAGON-B troponin T substudy. Circulation 2001;103:2891-6.

8. Heeschen C, Hamm CW, Goldman B, Deu A, Langenbrink L, White HD, for the PRISM Study Investigators. Troponin concentrations for stratification of patients with acute coronary syndromes in relation to therapeutic efficacy of tirofiban. Lancet 1999;354:1757-62.

9. Heeschen C, Hamm CW, Bruemmer J, Simoons ML, for the CAPTURE Investigators. Predictive value of $\mathrm{C}$-reactive protein and troponin $\mathrm{T}$ in patients with unstable angina: a comparative analysis. J Am Coll Cardiol 2000;35:1535-42.

10. Hamm CW, Heeschen C, Goldmann B, et al, for the CAPTURE Investigators. Benefit of abciximab in patients with refractory unstable angina in relation to serum troponin $\mathrm{T}$ levels. $\mathrm{N}$ Engl $\mathrm{J}$ Med 1999;340:1623-9.

11. Lindahl B, Venge P, Wallentin L, for the FRISC Study Group. Relation between troponin $\mathrm{T}$ and the risk of subsequent cardiac events in unstable coronary artery disease. Circulation 1996;93:1651-7.

12. DeFilippi CR, Parmar RJ, Potter MA, Tocchi M. Diagnostic accuracy, angiographic correlates and long-term risk stratification with the troponin $\mathrm{T}$ ultra sensitive rapid assay in chest pain patients at low risk for acute myocardial infarction. Eur Heart J 1998;19 Suppl N:N42-7.

13. Morrow DA, Cannon CP, Rifai N, et al., for the TACTICS-TIMI 18 Investigators. Ability of minor elevations of troponins $\mathrm{I}$ and $\mathrm{T}$ to predict benefit from an early invasive strategy in patients with unstable angina and non-ST elevation myocardial infarction: results from a randomized trial. JAMA 2001;286:2405-12.

14. Hyde TA, French JK, Wong C-K, et al. Four-year survival of patients with acute coronary syndromes without ST-segment elevation and prognostic significance of $0.5 \mathrm{~mm}$ ST-segment depression. Am J Cardiol 1999;84:379-85.

15. Cannon $\mathrm{CP}, \mathrm{McC}$ abe $\mathrm{CH}$, Stone $\mathrm{PH}$, et al. The electrocardiogram predicts one-year outcome of patients with unstable angina and non-Q-wave myocardial infarction: results of the TIMI III registry ECG ancillary study. J Am Coll Cardiol 1997;30:133-40.

16. Areskog INM, Areskog N-H, Swahn E, et al. Very early risk stratification by electrocardiogram at rest in men with suspected unstable coronary heart disease. J Intern Med 1993;234:293-301.

17. Diderholm E, Andren B, Frostfeldt G, et al, for the Fast Revascularization during Instability in Coronary artery disease (FRISC II) Investigators. ST depression in ECG at entry indicates severe coronary lesions and large benefits of an early invasive treatment strategy in unstable coronary artery disease. Eur Heart J 2002;23:41-4.

18. Kaul P, Fu Y, Chang W-C, et al., for the PARAGON-A and GUSTO-IIb Investigators. Prognostic value of ST-segment depression in acute coronary syndromes: insights from PARAGON-A applied to GUSTO-IIb. J Am Coll Cardiol 2001;38:64-71.

19. The PARAGON-B Investigators. Randomized, placebo-controlled trial of titrated intravenous lamifiban for acute coronary syndromes. Circulation 2002;105:316-21.

20. Hamm CW. Cardiac biomarkers for rapid evaluation of chest pain. Circulation 2001;104:1454-6.

21. Risk Adjustment for Measuring Healthcare Outcomes. In: Iezzoni LI, editor. Chicago, IL: Health Administration Press, 1997.

22. Wallentin L, Lagerqvist B, Husted S, et al., for the FRISC-II Investigators. Outcome at one-year after an invasive compared with a noninvasive strategy in unstable coronary artery disease: the FRISC-II invasive randomized trial. Lancet 2000;356:9-16.

23. Cannon CP, Weintraub WS, Demopoulos LA, et al., for the TACTICS-Thrombolysis in Myocardial Infarction 18 Investigators. Comparison of early invasive and conservative strategies in patients with unstable coronary syndromes treated with glycoprotein IIb/IIIa inhibitor tirofiban. N Engl J Med 2001;344:1879-87.

24. Holmvang L, Luscher MS, Clemmensen P, et al., and the TRIM Study Group. Very early risk stratification using combined ECG and biochemical assessment in patients with unstable coronary artery disease (a Thrombin Inhibition in Myocardial Ischemia [TRIM] substudy. Circulation 1998;98:2004-9.

25. Jernberg T, Lindahl B, Wallentin L. The combination of a continuous 12-lead ECG and troponin T: a valuable tool for risk stratification during the first 6 hours in patients with chest pain and a nondiagnostic ECG. Eur Heart J 2000;21:1464-72. 